\title{
A sociologia das finanças e a nova geografia do poder no Brasil*
}

Roberto Grün

Introdução

Se é verdade que a sociologia se ocupa prioritariamente dos leftovers, então poucos espaços sociais seriam menos propensos a atrair sua atenção do que aquele ocupado pelas finanças. Entretanto, os últimos anos assistiram a um grande aumento de interesse pelo tema na disciplina. Podemos falar de uma "préhistória" da disciplina no espaço germânico do início do século XX. Ele passa por um interessante opúsculo deWeber ([1898] 1987) sobre o funcionamento das bolsas de valores, mostrando, contra os críticos antifinanceiros de seu tempo, sua utilidade para economias capitalistas que queriam se desenvolver; pela justaposição entre economia esociologia marxistas presente no trabalho clássico de H ilferding (1981) e, de maneira mais sistemática, na FinanzSociologie de Schumpeter (1991) e cujo autor atualmente mais conhecido é Guex (2003).

U $m$ dos caminhos que leva à sociologia das finanças passa pela versão mais recenteda sociologia econômica. Aqui, a maior parte dos autores entra no assunto a partir da sociologia das organizações, em especial de sua vertenteneo-institucional. Se nos anos de 1980 a grandequestão da disciplina era dar conta da difusão das técnicas de administração industrial japonesas no $O$ cidente (cf. Cole, 1979; Powell e D imaggio, 1991), a década seguinte assistiu a um interesse crescente pela compreen são dos mecanismos quetor-
* Esse texto foi escrito a partir de dados coletados em pesquisas financiadas pela Fapesp e pelo CN Pq. Agradeço às duas entidadespelos auxílios prestados. 
navam as empresas e demais organizações cada vez mais suscetíveis aos comandos oriundos do mercado financeiro (cf. Dimaggio, 2001; Fligstein, 2001). D essa maneira, em especial a partir da segunda metade daquela década, o espaço das finanças torna-se um assunto relevante para diversos autores da disciplina. No caminho em direção ao espaço financeiro, os autores da sociologia das organizações e econômica acabam encontrando o grupo que se ocupa da discussão sobre model os de capital ismo (cf. G uillén, 1994; H ollingsworth eBoyer, 1997; Streeck eC rouch, 1997; Guillén, 2000). Esses últimos, de origem mais heterogênea, advêm, além da sociologia, da ciência política eda economia política. E o ponto deencontro, bem caracterizado no final dos anos de 1990, éa discussão da governança corporativa, o conjunto de tecnologias sociais de base financeira que estariam (cf. Lane, 2003), ou não (cf. Streeck, 2001), produzindo uma homogeneização das estruturas organizacionais, produtivas, financeiras e de relações industriais dos países capitalistas modernos.

O utro caminho, mais recente, é o iniciado nos estudos sociais sobre a ciência (cf. M ackenzie, 2003c). As finanças tornam-se interessantes àqueles autores provavelmente pelo papel saliente e auto-suficiente que elas adquiriram na sociedade contemporânea. Replicando as pretensões analíticas do chamado "programa forte da sociologia da ciência", aqui a ambição é abrir a caixa-preta que torna aquela esfera ao mesmo tempo respeitada, temida e incompreensível para o restante da sociedade (I dem, ibidem). U m grupo de trabal hos empíricos tem como alvo a relação entre seres humanos e instrumentos na construção da sociabilidade dos espaços financei ros internacionais (cf. Knorr-C etina e Bruegger, 2002), enquanto outro tenta penetrar a lógica interna dos principais instrumentos de trabal ho das finanças modernas (cf. M ackenzie, 2003a).

O s interesses e as abordagens são assim diferentes, mas a chave explicativa de ambos converge para explicar o comportamento dos agentes na esfera econômica por meio da ação de processos de mimetismo. Esse caminho confronta a explicação da teoria econômica que se ocupa das finanças, que prevê axiomaticamente a racional idade absoluta dos agentes ou limitações cognitivas ao seu uso. A relação de cada uma das vertentes com a economia financeira - o ramo da teoria econômica que explica (e produz, segundo vários analistas) os mercados financeiros e também pretende uma teoria "limpa" (cf. H irsch, 1990) sobre os fenômenos organizacionais - é bem diferente. Essa especialidade desenvolveu-se vertiginosamente nos últimos vinte anos, em estreita sinergia com a internacionalização e o desenvolvi- 
mento dos mercados financeiros em geral (cf. Fligstein eFriedland, 1995). D e um lado, ela propõe racionalizações teóricas robustas para justificar as tendências ideológicas atuais na gestão empresarial, tais como preferência pronunciada por privatização de serviços públicos, enxugamento organizacional, terceirizações e remuneração variável para os funcionários das empresas (cf. Fama, 1980). D e outro, desenvolve instrumentos de gestão de ativos e passivos financeiros sem os quais dificilmente poderíamosimaginar a extensão do volume das transações nos mercados atuais (cf. Bernstein, 1992).

Levando em conta suas respectivas origens, não épor acaso quea primeira vertente sociológica que apresentamos se ocupa prioritariamente em discutir os efeitos da aplicação dos preceitos da economia financeira sobre as organizações (cf. Dimaggio, 2001; Fligstein, 2001), enquanto a segunda esforça-se por "abrir a caixa-preta" que explicaria o funcionamento dos novos instrumentos postos à disposição dos financistas (cf. Knorr-C etina e Bruegger, 2002; M ackenzie, 2003b). A primeira de nossas origens sociológicas acaba assim definindo um perfil de análise que confronta diretamente a economia financei ra, criticando seus pressupostos ideológicos, métodose resultados. Por sua vez, a segunda encara os desenvolvimentos da economia financeira mais como um objeto de análise equival ente aos artefatosfísicose cognitivos formados a partir dos enunciados científicos oriundos da física ou da biologia, ainda que também avancena contestação das razões de funcionamento dos instrumentos financeiros (cf. M ackenzie, 2003a; M ackenziee Millo, 2003).

Os usos da economia financeira

0 desenvolvimento da economia financeira pode ser entendido como parte do processo de recuperação do controle social pelo conservadorismo norte-americano depois do susto do final dosanos de 1960 (cf. Guex, 2003). No espaço econômico, ela operacionaliza e justifica tanto a retração e reconfiguração do papel dos Estados no fomento econômico e na esfera social - a idéia de Estado mínimo - como, na esfera das empresas, estabelece uma racional ização para a recuperação do lucro líquido dos acionistas e do seu controle mais efetivo em relação às ações dos executivos profissionais a operacionalização da "boa" governança corporativa. Em ambos os casos, quem disciplina tanto Estados como empresas são os mercados financeiros. Assim, o fenômeno recente que os leigos catalogam como a hipertrofia 
incompreensível da esfera financeira em detrimento da produção de bens "reais" e da ação dos Estados nas mais diversas esferas é aqui conceituado como o desenvolvimento sadio de uma esfera de regulação social mais eficiente do que as anteriores, inclusive, implicitamente, a da soberania popular expressa na representação política.

$\mathrm{N}$ a esfera empresarial, a "boa" governança corporativa pode ser vista como a consagração do entendimento de que as empresas são dos acionistas e, assim, que o poder dos administradores profissionais é espúrio e deve ser constantementemonitorado para "alinhar seusinteresses" aos dos verdadeiros donos. Esse enunciado contrapõe-se às idéias do poder da tecnocracia, consagradas em G albraith (1978) e que começaram a tomar a forma atual em Berle, M eans et al. (1932). Analítica e ideologicamente, não é exagero dizer que ele representa uma verdadeira revolução cognitiva. A sociologia e a teoria das organizações tradicionais ol ham as empresas sobretudo a partir do ponto de vista dos seus agentes internos. Essa visão se institucionaliza academicamentena disciplina "O rganizational Behaviour" dos M BAsedas escolas de administração, ganhando o nome de "Introdução à administração" e "Teoria das organizações" em solo brasileiro, e educando a sensibilidade de milhões de estudantes em todo o mundo. $\mathrm{N}$ a maior parte das vezes aquele agente interno é o gerente procurando maior eficiência na ação de seus subordinados e, no grupo minoritário dos críticos, o funcionário subordinado que tenta defender-se da pressão da hierarquia. Já na abordagem da economia financeira, o ponto de vistaéo do acionista, o qual, por definição, está sendo enganado pelos administradores profissionais, cujo interesse fundamental seria o de ganhar status e se enriquecer em detrimento da maximização do retorno do capital investido pelos acionistas.

0 problema da dissociação entre acionistas eadministradores profissionais era originalmente típico dos Estados U nidos e refletia as peculiaridades do caminho histórico da relação entre empresas e mercados financeiros daquele país, conforme está sugerido no título Strong managers, weak owners (Roe, 1994). Nos anos de 1970 e 1980, quando as correntes tradicionais dominavam a cena intelectual dos estudos organizacionais e a pujança industrial japonesa era louvada, a configuração norte-americana era vista como um problema. Afinal, os mercados financeiros daquele país exigiam fartas distribuições de lucros das empresas, obrigando-as a privilegiar o planejamento de curto prazo em detrimento das considerações estratégicas e, assim, impedindo-as de investirem em mudanças radicais que produziriam 0 catch-up capaz de recuperá-las diante do "desafio nipônico". 
No final dos anos de 1980, sob o efeito "ovo-galinha" da recuperação econômica das grandes empresas manufatureiras norte-americanas, do desenvolvimento de novos ramos industriais e de serviços ligados à informática e da consagração da então nova economia financeira, a questão foi reconceituada. A partir daquele momento, a relação empresas-mercado de capitais norte-americana, antes problemática, passou a ser vista como um trunfo. Ela passa a ser uma fonte poderosa de "governança" para as empresas daquele país, obrigando seus administradores profissionais a pensarem prioritariamente nos pontos que "realmente importam" aos acionistas - os lucros no curto prazo, seja por meio da distribuição de dividendos, seja por intermédio da valorização do preço e do aumento de liquidez das ações das empresas. Agora mais confiantes, os capitalistas de todo o mundo passaram a investir prioritariamente nas empresas norte-americanas, dotandoas de fundos para se desenvolver e ultrapassar a concorrência estrangeira, que correlativamente, por não adotar a mesma governança, perdia a preferência dos investidores. N esse sentido, nada mais sugestivo do que o título do Economist (1994) anunciando a inflexão: "Ready to take on the world". A partir daquele momento, são países como o Japão e a Alemanha, antes os gigantes da capacidade manufatureira, que se constituiriam nos problemas mais graves das economias desenvolvidas, já que não conseguiriam adaptar-se à flexibilidade que passa a ser a virtude mais apreciada pelos investidores'.

D e um passo, a configuração norte-americana torna-se um modelo de excelência, batizada de "boa" governança corporativa. Seguindo uma tendência quejá vimos para outras novidades do mundo econômico, ela vai ser conceitualizada e "empacotada" nas empresas de consultoria e nas grandes escolas de economia, de administração e de direito daquele país. A partir dessa plataforma compósita, a governança corporativa torna-se um artigo de exportação muito interessante. Esse produto peculiar, ao mesmo tempo econômico ecultural, produz ele mesmo seus corretoresinternacionais, que nos acostumamos a caracterizar como os "C hicago boys". Trata-se dos estudantes deeconomia, administração ou de direito latino-americanos que vão estudar nas universidades norte-americanas, eventual mentetambém trabaIhar no mercado financeiro daquele país ou nos órgãos econômicos multinacionais, para depois voltarem aos seus países de origem e ali se tornarem propagandistas e aplicadores das novidades com as quais tomaram contato no estrangeiro. 0 debate público está mais acostumado a notar esse tipo de ator quando ele se manifesta na discussão sobre o cotidiano da política eco-
1. E o remédio padronizado paraessa "elefantíase" passa a ser a flexibilização dos mercados detrabalho, dos espaços financeiros edas leis de proteção social. 
nômica, em especial nos países da América Latina. Já seu papel de interface mais generalizado, que inclui o pessoal que atua no setor privado como promotores de cau sas que sal varão os diversos "capital ismos nacionais", da Etiópia à Alemanha, como justamentea da "boa" governança corporativa, é menos notado (cf. D ezalay, 2004).

A "boa" governança corporativa ganha assim foros de universalidade e começa a ser exportada (O ECD , Forum for the Future, 2001). $N$ a segunda metade dos anos de 1990 abre-se um debate intenso sobre a sua "exportabilidade" nos países da Europa 0 cidental e no Japão. Seus adeptos - tipicamente as versões nacionais dos "C hicago boys", mas, mais amplamente, todos os interessados em subverter o status quo empresarial local - afirmarão que a "boa" governança corporativa é o supra-sumo da modernidade e, portanto, os países que não quiserem adotá-la estarão condenados ao atraso (cf. D ezalay e G arth, 2002a). Já seus críticos irão chamar a atenção para as peculiaridades e as virtudes diferenciais de cada país, dizendo também que a instalação da "boa" governança corporativa iria enfraquecer o tecido social dos países de tradição não anglo-saxã, em especial as sociais-democracias européias (cf. Roe, 2003).

\section{A sociologia e a governança corporativa}

Diante da expansão da "boa" governança corporativa, a sociologia econômica começa, em tons nitidamente críticos e céticos, negando a possibilidade da sua extensão, em especial nos países dotados de modelos de relações industriais desenvolvidos por inspiração social-democrata (cf. Guillén, 2000), para, no início do novo século, constatar a sua difusão na Europa O cidental e no Japão (cf. Streeck, 2001). D iante da evidência empírica, a sociologia econômica mainstream começa a abandonar o pressuposto, aos meus olhos economicista, de que a grande questão da "boa" governança corporativa é um debate sobre a eficiência relativa dos diversos "modelos de capitalismo" e passa a enxergar com maior nitidez a ação de diversos mecanismos sociais, não diretamente econômicos, que formatam a agenda econômica das sociedades. Parafraseando o termo taylorista, começa-se a falar na "boa" governança corporativa à norte-americana como um only way (ao contrário do best way da organização do trabalho que se queria científica) imposto aos atores por meio de pressões institucionais (cf. Lane, 2003). D ez anos depois do início do debate, podemos ver mais claramente que estamos diante da extensão do poder simbólico associado a um produ- 
to cultural bem legitimado: se no início a "boa" governança corporativa era apenas a solução adequada para os problemas societários norte-americanos, realmente sem sentido para ser adotada em configurações diferentes, el a passa a ser uma espécie de "santo remédio contra todos os males" - uma solução prévia para problemas nacionais os mais diversos, tanto os já definidos como aqueles que ainda não o foram.

É interessante ver como a questão se desenvolve no espaço intelectual que nos acostumamos a chamar de "sociologia francesa". Ali a análise sociológica dosfenômenos econômicos configura-se precocemente como uma empreitada mais próxima da análise cultural, fornecendo instrumentos para o estudo da difusão da "boa" governança corporativa como uma construção de sentido. Lá aparece um desenvolvimento peculiar. Ele se caracteriza pelo diálogo crescente entre sociólogos que se ocupam dos fenômenos econômicos e financeiros e as duas escolas econômicas "autóctones", da regulação e das convenções fortemente implantadas naquele país e provavelmente "pólos dominados" da disciplina no plano internacional². Temos ali duas crossfertilizations bem caracterizadas. A primeira delas surgida na gênese conjunta entre a escola das convenções e o grupo de sociólogos reunidos em torno da teoria do diálogo proposta por Boltanski eT hévenot (1991). A segunda, que se explicitou mais recentemente, é composta pelo grupo formado em torno de Bourdieu e a escola da regulação (cf. Lordon, 2002; Boyer, 2003). E, curiosamente, as relações entre as duas escolas econômicas acabam construindo uma ponte entre as escolas sociológicas, menos evidente, mas cada vez mais percebida.

Em ambos os casos, a sociologia econômica desenvolve-se em ateliês não especializados tematicamente, nos quais a convivência se faz em torno de pressupostos teóricos e metodológicos. Vai daí queum dos resultados da eintrae-fertilização das duas disciplinas em solo francês produz esse padrão de análise no qual o estudo dos fenômenos de difusão de práticas econômicas faz-se na chave mais próxima daquela normalmente empregada para dar conta da difusão de idéias e de práticas culturais em geral. Trata-se de uma divisão de trabal ho quase sistemática, em vez da competição implícita que se trava no universo anglo-saxão. Esse propósito ganha ares programáticos em um texto recente de Boyer (2003), talvez o principal economista da escola da regulação, num número especial de Actes de la Recherche, a revista fundada e dirigida por Bourdieu, que foi dedicado à repercussão da obra daquele sociólogo recentemente falecido. D essa forma, o foco das investigações é dirigido mais para a dinâmica do relacionamento concreto
2. No espaço dasociologia dos intelectuais, que não é nosso assunto no momento, seria interessante pesquisar as razões queimpelem essediálogo inesperado entre disciplinas que estão cada vez mais dissociadas no âmbito internacional. 
3. Diversos trabalhos, como D ezalay e Institut des $\mathrm{H}$ autes Études sur la Justice (1993); D ezalay (1994); D ezalay e Sugarman (1994); Lebaron (2000); D ezalay e G arth $(2002 a, b)$ e Lordon (2002), são bons exemplos desse gênero de abordagem. entre os diversos grupos de atores, em especial dos conflitos entre os diversos setores das elites econômicas, políticas e culturais, do que para uma previsão abstrata do comportamento de atores, inferida de figurinos saídos de modelos nacionais de comportamento ${ }^{3}$.

Para uma sociologia das finanças brasileiras

N o Brasil, a sociologia das finanças pode oferecer um novo foco para a análise dediversos fenômenos do presente emesmo do passado maisdistante. Podemos ver, nos diversos ciclos econômicos pelos quais passamos, a existência de uma tensão essencial entre produtoresfísicos demercadorias açúcar, café, al godão, os mais diversos produtos industriais - e aqueles que comercializam efinanciam a produção (cf. Faoro, 1975; Saes, 1986; M ello, 1995). N os ires-evires das diversas configurações, uma sociologia econômica (das finanças) dirigiria nosso ol har para a discussão sobre os critérios de repartição da riqueza produzida, opondo as razões dos produtores às dos distribuidores e financiadores, internos e externos. 0 levantamento da construção dos argumentos, incluindo sua origem, montagem e remontagem diante dasoposições, seguido da análise das práticas que suscitam, tanto nos atores diretamente interessados como nas esferas governamentais que constroem o pano de fundo institucional que torna os mercados possíveis, chegando ao critério dejustiça que acaba preval ecendo em cada situação, éuma sugestão facilmente proposta por uma das vertentes analíticas. 0 outro lado é a análise da construção dos atores e seus contenciosos por meio de suas práticas- as argumentativas eas outras. Aí a noção de campo mostra grande utilidade. O riginalmente uma marca característica do grupo reunido em torno de Bourdieu, ela tem sido adotada, de maneira explícita ou implícita, em diversas propostas institucionalmente distantes daquele autor. U ma ligação muito interessante é o seu uso no aprofundamento da investigação sobre a história dos conglomerados empresariais norte-americanos, iniciada por Chandler (1962) e robustecida por seu uso em Fligstein (1990).

No estudo do Brasil recente, um tipo de contribuição que talvez ainda esteja faltando são análises da influência da inflação sobre a sociabilidade, a exemplo de trabalhos sobre a H ungria e a Alemanha (cf. Ringer, 1969). Sabe-se que os efeitos de surtos inflacionários ou hiperinflacionários, assim como crises econômicas profundas, como a de 1929, geram marcas indeléveis nas gerações que passaram por elas, diferenciando-as das que vieram antes edepois (cf. Elder, 1999). 0 utro ponto éo quepoderíamoschamar de 
"etno-finanças" - a análise das subjetividades e dos comportamentos dos indivíduos diante dos constrangimentos financeiros. Temos exemplos esparsos de autores que passam pelo tema incidental mente, como $\mathrm{C}$ andido (1987) em relação à reciprocidade e o crédito popular, mas não abordagens sistemáticas. 0 utra intersecção que falta é a que explicaria 0 aprendizado social do uso das equivalências de valor no regimeinflacionário, tais como 0 mecanismo de correção monetária, que durou longos anos, e aquele das U nidades R eferenciais de Valor - as U RV s-, que foram adotadas no início do Plano Real. No espaço mais restrito da sociologia das organizações e do trabal ho no Brasil, a inflação persistente inflou a área financeira das empresas em detrimento das outras, eessa peculiaridadeinfluenciou nosso padrão de relações industriais e também as escol has entre as carreiras profissionais ligadas ao mundo das empresas. E, ainda mais recentemente, salta aos ol hos a hipertrofia do setor de empresas financei ras e bancos voltad os para o segmento do crédito popular, que alavanca o consumo de indivíduos (e famílias?) de renda relativamente baixa, ainda quea taxas de juros inacreditavelmente altas, dificilmente toleráveis para outros grupos sociais. $N$ esse sentido, escutemos as palavras de M ario Werneck, diretor da Fininvest, uma das maiores financeiras paulistas especializadas no crédito popular, referindo-se às decisões de tomada de empréstimo de seus clientes: "Eles não pensam como nós" (Gazeta M ercantil, 2001). Explorar os mecanismos de controle do pagamento desenvolvidos pelos credores, assim como as razões que impelem os devedores a aceitarem as regras dos empréstimos que são concedidos, éuma empreitada sociológica de altíssi mo interesse e fôlego.

Sociologia das finanças, sociologia do poder

Como um capítulo da sociologia das elites edo poder, creio quea sociologia das finanças pode contribuir para esclarecer o jogo de poder no Brasil contemporâneo. A partir dos anos de 1990, em especial durantea oitava de Fernando $\mathrm{H}$ enrique $\mathrm{C}$ ardoso, assistimos a um enorme desenvolvimento do peso relativo do setor financeiro na nossa sociedade, que ofuscou até mesmo a hipertrofia do setor ocorrida no período militar. Chamam a atenção e o clamor popular o crescimento dos lucros dos bancos ea persistência das altas taxas de intermediação (spreads), que tornam o financiamento externo das empresas muito caro. D essa maneira aparecem os val ores dos juros que o país paga aos seus credores internos e externos, além dos lucros afixados nas demonstrações contábeis dos bancos. 
4. Falo aqui especificamente da arbitragem financeira. H á outros tiposdearbitragem, principalmente na área le gal, que consistem na tentativadeseencontrar soluções privadas para questões comerciais ou trabal histasque seriam muito custosas ou de moradas se fossem le vadas às instâncias jurídicas tradicionais.
M as uma parte menos visível da configuração, e provavelmente a mais significativa por causa dos seus impactos mais gerais sobre a sociedade, é o desenvolvimento de um novo circuito de intermediação, amplo e diversificado, dotado de certa independência em relação ao tradicionalmente operado pelos bancos comerciais. A importância do novo circuito deve-se às novas relações que ele engendra com os setores não financeiros e à nova justificativa ideológica que ele propõe diretamente para sua existência e, indire tamente, para toda a sociedade. N esse caminho são recontextualizados diversos fenômenos e institucionalidades, em especial os da esfera organizacional, como as empresas e as agências que promovem o interesse geral da nação. 0 novo circuito desenvolve-se a partir de dois halos de legitimidade. 0 primeiro tem a ver com o alarido nacional contra os custos da intermediação financeira tradicional. U ma vez que os bancos cobram muito pelo seu papel de recolher, realocar e securitizar a poupança nacional, a sociedade precisa desenvolver outros circuitos de intermediação, a custos mais baixos. 0 outro, do qual a grita brasileira talvez seja em parte um reflexo, corresponde à criação de novos circuitos, o chamado "big bang financeiro", deflagrado para facilitar o desenvolvimento de um mercado financeiro realmente internacional, que permita uma al ocação de capitais de acordo com as oportunidades, menos submetida às amarras da intervenção das autoridades econômicaslocais(cf. Bernstein, 1992; C ohen, 1998). Essa liberalização tornaria os investidores mais seguros, transformando mais facilmente suas poupanças paradas em capital produtivo. Além disso, as empresas e os governos tornar-se-iam mais racionais, pois seriam obrigados a focalizar sua atenção na criação de oportunidades não só para a atração de novos capitais, mas também para a permanência daqueles já aplicados.

$\mathrm{N}$ a nova situação configura-se uma lógica tanto de atuação como de justificação, baseada na idéia de "arbitragem" (cf. M ackenziee M illo, 2003; B eunza, 2004). 0 setor bancário tradicional justifica-se perante a sociedade como um prestador de serviços para os agentes econômicos e a população em geral. E ainda que no Brasil dos últimos anos ele tenha se concentrado na rolagem das dívidas do setor estatal, as manifestações públicas de seus representantes lembram sempre que essa situação é transitória e que os bancos voltarão, assim que puderem, ao seu papel tradicional de fomentadores da produção. Já para os agentes que participam da arbitragem ${ }^{4}$, 0 novo papel do setor financeiro seria o de detectar o funcionamento inadequado de empresas ou de governos e, em seguida, promover a retificação dos comportamentos errados. A correção faz-se pelo ataque, necessaria- 
mente impiedoso, à moeda e aos títulos do país ou aos títulos das empresas "mal administradas". Precavendo-se contra esses ataques, governos e empresas manter-seiam "na linha". Por sua vez, os árbitros prestariam um enorme serviço às sociedades, monitorando o comportamento desses agentes que em princípio tenderiam a atuar de maneira inadequada. Aqui o darwinismo social nem mesmo é disfarçado. E a grande pergunta passa a ser quando, como e por meio de que tipo de ação legitimadora, realizada por quais agentes, a sociedade passa a aceitar ou a tolerar a ação desimpedida dos árbitros financeiros 5 .

Podemos ver a evolução da atuação desses novos agentes no Brasil a partir justamente dos instrumentos financeiros que eles propõem aos agentes econômicose, de maneira mais ampla, à sociedade. 0 mais evidente, euma espécie de protótipo de diversos novos produtos, é o chamado "fundo de recebíveis", no qual, de um lado, os valores das empresas a receber no futuro, como cheques pré-datadosou prestações vincendas oriundas devendasa prazo, são antecipados mediante uma taxa de desconto, permitindo às empresas reaver o capital empregado na antecipação e real ocá-lo nas operações correntes (cf. D uarte, 2004; G alvão, 2004). D e outro lado, o operador financeiro, que constitui uma firma para essa finalidade, tem de conseguir os recursos para adiantar à empresa. Para isso, deve encontrar financiadores dispostos a "comprar o risco", ou seja, a aceitar comprar um título produzido pela agregação e desagregação dos diversos recebíveis colocados na mesma cesta.

A lógica da operação é a da "securitização": o risco de descontar previamente um cheque prédatado e deparar-se no vencimento com um cheque sem fundos, perdendo todo o investimento, é relativamente alto, podendo demover o nosso investidor. Entretanto, esse investidor fica muito mais "coberto" se tiver em mãos um título querepresenta 1/1000 deum conjunto de risco de centenas de cheques pré-datados, dos quais alguns poderão revelarsesem fundos, mas a maioria não. A questão aí passa a ser a taxa de desconto que rentabiliza o investimento mesmo diante da expectativa de al guns cheques não serem pagos. Já o promotor da operação deve cobrar da empresa uma taxa de desconto menor do queaquela queum banco cobraria (senão a empresa recorreria ao banco) e oferecer ao investidor uma remuneração mais alta do que a obtida em aplicações bancárias, em geral de menor risco.

Em suma, a mágica está no processo de agregar os riscos, "securitizar" o montante e encontrar compradores para cada security. No caminho tradicional, os cheques ou confissões de dívida seriam encaminhados aos bancos
5. U ma das pistas é aquela seguida pelos "bourdieusianos" quanto aosinvestimentosem legitimação, ao mesmo tempo econômicos e emocionais, de figuras como Georges Soros (cf. Guilhot, 2004). 
6. N ormalmenteasempresas de factoring são consideradas limítrofes entre a intermediação financeira legal ea agiotagem.
7. A expansão não é, evidentemente, contínua esem tropeços. Em meadosde2004, vemos uma retração do processo, com uma concentração dos investimentosnosnovosfundosjá considerados de alta performance em detrimento daqueles que se estabeleceram mais re centemente (cf. Rio, 2004b).

8. Ver http:/www.inves topedia.com/terms/p/ privateequity.asp. comerciais, que os descontariam, usando indistintamente seus capitais próprios ou de seus depositantes. Um caminho paralelo, mas mais caro, é a empresa enviar os cheques para uma firma de factoring, menos formalizada do que um banco e por isso apta a realizar descontos oriundos de operações informais, e cobrar mais por isso ${ }^{6}$. Assim, o fundo de recebíveis é tão mais atrativo para as três partes envolvidas quanto maior forem as taxas de juros cobradas pelos bancos. É interessante notar que os bancos estatais passaram em 2004 a oferecer o produto como uma forma de fomento possível em tempos de restrições orçamentárias e de queixas generalizadas contra a pouca ação governamental na promoção da atividade econômica (cf. Laier, 2004).

Tangidos pela concorrência, al guns bancos passaram mais recentemente a oferecer produtos análogos, mas de modo geral évisível a pequena reação do setor à generalização da criação dos novos fundos. Aos meus olhos, essa reação pouco intensa revela uma situação de baixa legitimidade do setor bancário brasileiro. E, irônica - e sócio-logicamente - , quem se aproveita dela não são os setores prejudicados pela hipertrofia financeira, mas uma nova geração de financistas que encontra espaços econômicos e legais para se estabelecer.

As novas interações entre o espaço financeiro e o mundo das empresas

Entre os diversos novos produtos que se destacam - lembrando sempre que eles representam também novos atores que se estabelecem por conta própria, quando, em etapas anteriores, o normal seria que fossem empregados dos bancos e financeiras - creio que vale a pena chamar a atenção para dois outros: os gestores de fundos de investimentos independentes e, pelo seu papel peculiar na relação entre o setor financei ro eas empresas, os chamados fundos de private equity. O s primeiros desenvolveram-se exponencialmente nos últimos anos (cf. D 'Ambrosio, 2003; D ávila, 2004; D 'Ambrosio, 2004). N eles vemos os novos agentes proporem, para clientes de alto poder aquisitivo, investimentos sofisticados mas não necessariamente mais arriscados para quem conhece os meandros dos mercados financeiros e, certamente, diminuindo o espaço para a atuação dos bancos?

Em tese, o negócio de private equity é qualquer grupo de investidores que deci de se associar para aplicar numa empresa. Em geral, ela não é cotada nas bolsas de val ores e representa uma novidade de produto ou de mercado $^{8}$. A normatização do uso dos private equities é considerada pelos órgãos de fomento internacionais um dos componentes essenciais do 
capitalismo contemporâneo, e é assim que o governo brasileiro, em carta de intenções dirigida ao FM I, se apressa em estabelecer o quadro legal para o desenvolvimento do produto (Valor Econômico, 2003b).

No caso específico dos private equities, que estão se desenvolvendo no Brasil, um operador enxerga uma oportunidade numa empresa, em geral média ou grande, na qual poderia obter mais rentabilidade do que a que seus atuais controladores têm obtido. Em seguida, o operador desvela al gumas opções: a mais comum ébuscar um conjunto deinvestidores que se associam na compra da empresa por meio da aquisição detítulos de uso específico para essa finalidade, emitidos pelo operador ${ }^{9}$. $\mathrm{N}$ a lógica do sistema, esses títulos deveriam ter liquidez e se transformarem em ativos equivalentes às ações ou certificados de depósito bancário, no sentido de poderem ser facilmente negociados na medida das necessidades ou conveniências de seus portadores. Entretanto, no Brasil, eles ainda não al cançaram essa característicae, portanto, não épor acaso que os agentes econômicos mais cautelosos, como os fundos de pensão, relutam em adquiri-los (cf. Fortunato, 2003) e as agências financeiras multinacionais, o FM I na frente, cobram do Brasil medidas legais para promover a liquidez dos títulos de private equity (Valor Econômico, 2003b).

D o administrador profissional nomeado pelos proprietários das private equities, espera-se que consiga maior eficiência financeira para a empresa que foi objeto do investimento. Em termos sociológicos, podemos dizer que 0 aumento de rentabilidade é conseguido por meio do enquadramento da situação vivida pela empresa como de crise, percepção essa que é magnificada pela mudança da direção geral. U ma vez instal ada essa percepção, abrese espaço para a adoção de medidas drásticas pela direção da empresa sem que se desenvolva uma resistência proporcional dos empregados ou dos cre dores. Essas medidas podem ser a renegociação das dívidas da empresa, tanto no montante como nos prazos de vencimento, a intensificação do trabalho, a demissão de pessoal e o deslocamento de chefias, a instalação de sistemas de informações como os ER Ps, que embutem transformações organizacionais de monta, 0 abandono de linhas de produtos ou de serviços e outros (cf. Koch, 2001). E, genericamente, a situação de crise permite uma quebra geral dos circuitos de reciprocidade desenvolvidos na história da empresa entre ela, seus funcionários e outros stakeholders (cf. Grün, 1999).

É interessante notar que os novos administradores que costumam trabal har nesse gênero de empreitada são, antes de tudo, especialistas no ramo de "salvamento de empresas", e não conhecedores da especificidade do ne
9. A outra seria propor aos proprietários da empresa um contrato de gestão, no qual ele assumiria a gerência dos negóciose em troca re ceberia parte das ações da empresa ou dos lucrosadicionais gerados pela sua intervenção. 
gócio da empresa que está sendo reorganizada. A visão financeira dos negócios que normalmente Ihes é típica e o desconhecimento da história da empresa tornam a quebra de reciprocidades menos traumática, mais manejável pelos operadores emais aceitável (ou vista como mais inevitável) pelos prejudicados. Estamos assim diante de uma espécie de "ignorância funcional". Ela é funcional porque as reciprocidades que normalmente ligam os participantes de uma empresa ou ramo econômico - fruto da interação inextricavelmente econômica e social que se produz no convívio - se anulam ao não encontrarem uma equivalência financeira ou contábil que possa ser reconhecida pelos novos atores. Abre-se aqui uma questão interessante: para maior parte dos membros da chamada nova sociologia econômica, em especial aqueles mais influenciados por Granovetter e Swedberg (cf. Granovetter e Swedberg, 1992; G ranovetter, 1995), o papel da disciplina é mostrar o entrelaçamento social quetorna a atividade econômica possível e determinada. Acredito queBourdieu (2000) dá um passo além, ao mostrar que o papel da teoria econômica atual é legitimar e permitir a disjunção do econômico e do social, referendando justamente a ultrapassagem dos constrangimentos da sociabilidade.

\section{A "boa" governança corporativa e a competição entre as elites}

A configuração surgida da difusão das private equities no solo empresarial brasileiro pode ser entendida como uma especificação, no universo das empresas de capital fechado, das idéias associadas à "boa" governança corporativa. A difusão da "boa" governança corporativa no Brasil revela uma faceta talvez ainda pouco explorada da dinâmica cultural das sociedades capitalistas, da sua relação com a dinâmica econômica e da relação entre as diversas elites que compartilham o nosso campo do poder. Inicialmente um tema dos nossos "C hicago boys", ela se configurava como um claro instrumento dos financistas diante dos outros atores empresariais. 0 resultado da tramitação da lei das SAS no Congresso nacional durante a legislatura entre 1999 e 2002 mostrou as limitações desse grupo. Ainda que os financistas e advogados interessados no tema tenham convencido os legisladores a aprovarem um texto considerado "contemporâneo", não foram capazes de evitar os vetos presidenciais que muito desfiguraram as intenções de dotar nosso mercado de capitais de regras equivalentes àquelas em vigor nos Estados U nidos, eassim ampliar as possibilidades de negócios do setor. 
D urante a campanha eleitoral de 2002, o tema acabou sendo incorporado pelo grupo de Lula, que já estava inserido no universo dos fundos de pensão. A partir daquela janela, os lulistas desenvolveram contatos com vários setores do mercado de capitais, culminando com a célebre visita de Lula à Bovespa, quando foi firmada uma espécie de pacto (cf. M urphy, 2002). A partir daí a questão da governança corporativa ganhou outra roupagem. Estávamos diante de um tema excelente para realizar a ponte entre os dois setores. Encampando a defesa do caráter sagrado das poupanças dos operários, Lula e seu séqüito avocavam a bandeira que aparentementeinteressava apenas a setores do mercado de capitais. Situação curiosa, mas também um ardil da razão: por meio da governança corporativa os Iulistas juravam fidelidade ao capitalismo e, ainda mais, na sua versão mais moderna e legitimada pelos fazedores de opinião. D o seu lado, os financistas que dependiam da vitalidade do mercado de poupanças internas encontravam no grupo um aliado inesperado na luta de vida ou morte que travavam contra os setores maisinternacionalizados do mundo dos investimentos, os quais, nosúltimos tempos, direcionavam cada vez mais as aplicações de seus clientes para fora do país.

É interessante notar que a aprovação da lei das SAS no Congresso foi o resultado de um longo e meticuloso processo de convencimento dos congressistas e fazedores de opinião com acesso à mídia e aos foros econômicos. Em linguagem sociológica, assistimos a um intenso processo de construção de legitimidade para o tema. Em 1995 foi fundado o Instituto Brasileiro de Governança Corporativa, que tentou popularizar o tema no espaço da discussão econômica e legal. Foram promovidos vários eventos, tanto por órgãos públicos (BN D ES, entre outros) como por organizações privadas nacionais e internacionais. D o seu lado, a imprensa foi acionada diversas vezes para incensar a novidade. Entretanto, o processo foi barrado justamente no espaço do Executivo, tido como favorável e compatível com as tendências modernas de organização capitalista, exatamente onde el e parecia ter total legitimidade (cf. Grün, 2003a).

Creio que uma boa hipótese para o paradoxo seria o fato de que os promotores iniciais da governança corporativa não conseguiram defender sua causa como de interesse geral da nação. D essa maneira, seus oponentes palacianos conseguiram obstar boa parte das modificações institucionais que eles consideravam importantes. U ma vez encampada pelos petistas, no auge de sua popularidade, a causa ganha outra dimensão. Agora são os representantes da classe trabal hadora fal ando no interesse dos seus representados 
imputados. E a "classe trabalhadora" acaba sendo considerada como o "povo em si".

As palavras fortes de Lula, em que "a proteção da sagrada poupança dos trabal hadores" é condição necessária para que a Bolsa se transforme numa alternativa para a aplicação dos fundos administrados, seguidas da apresentação de um novo projeto de lei por parte de Berzoini (cf. Allen, 2002), conferem à governança corporativa um tom emocional. Assim, ela se transforma numa espécie de cause celèbre, empalmada por empreendedores morais, eadquire assim um halo demovimento social contra o qual as resistências latentes, como aquelas pouco identificadas que produziram os vetos presidenciais à investida anterior dos nossos "cruzados", podem menos.

A "boa" governança corporativa entre a teoria econômica e as práticas sociais

A associação entre uma questão do mundo financeiro e uma forma organizacional típica para fazer avançar uma causa popular, ainda que contra-intuitiva, não é de manei ra nenhuma inédita. Avanços significativos da governança corporativa nos Estados Unidos no final dos anos de 1980 e início da década seguinte, só foram possíveis porque foi criado um ambiente de indignação popular contra os altos salários e 0 excesso de benefícios dos altos executivos das grandes empresas daquele país. Já no início do novo século estamos vendo a implantação da Lei Sarbannes-0 xley, outra rodada de aperfeiçoamento legal, que aparece no rastro dos escândalos da Enron e da Worldcomm (cf. Blair, 2003). Em ambos os casos, os avanços acontecem quando se rompe o proverbial politics \& business as usual isto é, quando o campo político é pressionado de fora por forças que normalmente não se constituem - a nossa heteronomia.

Também na Alemanha temos um quadro nuançado, no qual a "boa" governança corporativa avança empurrada por estímulos exteriores ao mundo financeiro e político. Ainda que os analistas esperassem uma resistência feroz do movimento sindical e dos social-democratas à sua difusão, eis que ela "arruma as cartas" dos adversários nos contenciosos da época da financeirização (cf. Streeck, 2001). A incorporação da M annesmann pela Vodafone em 2000 não só representou um ponto de inflexão na atitude dos atores sociais daquele país, como também deixou claras as nuanças da questão. Diante de dirigentes empresariais, banqueiros e acionistas alemães, interessados em fazer funcionar estratégias de "des-diversificação", que vaIorizavam os preços das ações mas rompiam os equilíbrios tradicionais das 
relações industriais no sistema renan $0^{10}$, os representantes dos trabal hadores passam a adotar uma atitude mais tolerante quanto a outros aspectos da "boa" governança corporativa, notadamente nas questões de transparência contábil, que são, afinal, um problema maior para qualquer representante sindical durante uma negociação (cf. Jackson, 2001). Isso sem falar que a posição de acionista dos empregados da empresa, que se esperava fosse exercida no sentido de evitar a incorporação, também assumiu uma forma imprevista: diante da valorização do preço das ações, provocada pela iminência do takeover, grande parte dos empregados-acionistas preferiu ou vender suas ações na alta, ou acompanhar os raiders britânicos, que prometiam aumentar ainda mais seus patrimônios ${ }^{11}$. E, para completar nossa roda de paradoxos, os social-democratas alemães, interessados em fazer desenvolver um mercado de ações mais aberto, acabaram mostrando-se mais favoráveis à "boa" governança corporativa do que seus adversários conservadores, aparentementeinteressados em preservar os antigos equilíbrios na relação entre grandes bancos e conglomerados industriais.

0 caso francês aparece como outro revelador importante, por meio de um rumoroso episódio envolvendo a consolidação hostil do sistema bancário privado daquele país no final dos anos de 1990 (cf. Lordon, 2002). Ali, os grandes financistas, arautos altissonantes das virtudes do capitalismo do tipo anglo-saxão, travaram uma guerra sansmerci pelo controledos grandes bancos. Tratou-se de uma seqüência de ofertas de compra hostis, cujas justificativas públicas foram variando ao sabor das conveniências comerciais do momento, deixando absolutamente transparentes que a "racionalidade capitalista" é um artifício retórico extremamente mal eável, da mesma natureza que outros argumentos normalmente considerados "menos sérios". $\mathrm{E}$, suprema heresia, mostrando como, no espaço dos grandes negócios que afetam a vida de milhões de cidadãos, os recursos e as paixões supostamente irracionais da política preponderam sobrea racionalidade econômica pretendida no discurso dos agentes.

N o Brasil, além da postura geral de Lula como candidato, creio que dois casos que se tornaram públicos merecem a atenção dos analistas, porque apontam as formas de adaptação que iremos aceitar ou desenvolver no futuro imediato. 0 primeiro éa operação de fusão (ou de venda) ocorrida entre a Ambev ea companhia belga Interbrew. Aqui, a discussão ésobre o destino das ações preferenciais possuídas pelos acionistas minoritários, em especial a Previ - Caixa de Previdência dos funcionários do Banco do Brasil (cf. The Economist, 2004; Rio, 2004a; Leonardo Attuch, 2004). 0 outro éo desfe-
10. No esquemaalemão que evoluiu a partir do final dos anos de 1940, osgrandes conglomeradosindustriais aproveitam os lucrose possibilidades de alavancagem maiores do que a mé diaem um setor dosseus negócios para apoiar os ramos cujos resultados do momento estão abaixo do esperado, mantendo assim a possibilidadedeplanificar osnegócios no longo prazo e permitindo 0 investimento em inovaçõestecnológicas U m dosprincipais efeitos dessearranjo é a possibilidade de manutenção dos postos de trabalho nos setores provisoriamente deficitários. E assim o esque ma alemão de segurançano emprego encontra a sua base sócio-lógica.

11.0 utro ponto éque a empresa tinha empreendido uma virada estratégica, diminuindo a importância de seu negócio siderúrgico tradicional eenveredando para o então florescente ramo das telecomunicações. Essecaminho tornou os empregados dos ramoshistóricosda empresa céticos quanto ao comprometimento da alta direção alemã com a continuidadedos 
negóciossiderúrgicose conseqüentemente, com a segurança dosseusempregos. Diantedesse"desinvestimento" prévio da direção da empresa no arranjo tradicional, os empregadostambém, de alguma forma, tiveram o enquadramento da questão liberado para pensarem prioritariamente como acionistas esó depois como membrosdeumacomunidade industrial, a qual, nesse momento, já estava mesmo esmaecendo (cf. Jackson, 2001). cho da disputa pelo controle da Brasil Telecom, opondo as grandes fundações de previdência privada das empresas estatais ao banco 0 pportunity (cf. Valor Econômico, 2003a; Vieira, 2003). 0 s dois episódios dizem respeito às relações entre acionistas de empreen dimentos importantes e podem constituir-sena "prova do pudim" do nosso mercado de ações e do futuro denossa "boa" governança corporativa. N os dois casos, a posição indefensável em que os fundos de pensão se encontram dificilmente poderia ser compreendida sem levarmos em conta a intromissão do governo federal anterior nos seus processos decisórios (cf. Grün, no prelo).

No presente, as regras da "boa" governança corporativa indicam-nos que os dois conflitos deveriam ser resolvidos a favor dos fundos de pensão, contra os novos atores financeiros que detêm o controle das duas empresas. No primeiro caso, pela compra pela Ambev das ações preferenciais, a um preço compatível com o valor estabelecido na fusão (tag along). N o segundo, pela entrega do controle empresarial aos fundos de pensão, que são, afinal, sócios majoritários das companhias que detêm o controle acionário da empresa. Entretanto, até o momento os novos banqueiros de investimentos conseguiram manter suas posições de confronto, mesmo diante de um poder executivo no qual vários indivíduos ligados aos fundos de pen são ocupam lugares de destaque. Entre outros atores, é interessante seguirmos os diretores da CVM - Comissão de Valores M obiliários, tanto os apontados no governo anterior como no atual (cf. Balarin, 2004).

Surge uma tensão bem clara entre os dois projetos de "financei rização": nos oito anos do governo anterior, os fundos de pensão eram atores suspeitos, porque "corporativos", e eram compelidos a se alinhar com os novos bancos de investimentos, tidos como a encarnação mesma da racional idade econômica. A idéia era de que os administradores e cotistas dos fundos de pensão só teriam a ganhar nas associações com os novos players, supostamente mais eficientes, racionais e honestos como gerenciadores de capitais. Assim, em qualquer pendência envolvendo administradores de fundos de pensão e novos banqueiros, os agentes do governo central demonstravam imensa simpatia pelos segundos atores e pouca compreensão pelas razões dos primeiros. Os diversos casos rumorosos envolvendo a privatização do setor de telecomunicações e elétrico, além da sistemática de fiscalização impingida aos fundos no período, atestam a impressão (cf. G rün, 2003b). No período que se abriu com o governo Lula, aparentemente a polaridade se inverteu, dando aos fundos o papel de "bom capital", porque de longo prazo e mais popular, e implicitamente catalogando os novos bancos de 
investimentos como associados ao capital volátil, tolerável dadas as circunstâncias, mas menos desejável (cf. Braga, 2003; Batista, 2003).

\section{Conclusão}

As nuanças que aparecem nos processos deadaptação nacionais aos constrangimentos financeiros mostram assim mudanças importantes em relação às situações anteriores, mas não o quadro de submissão absoluta de todos os homens diante de um novo deus.

0 mosaico ganha nitidez e o quadro sociológico se completa quando a idéia de "sociedade em rede" é levada em conta. H á um imenso investimento cultural no sentido de enquadrar o mundo em quevivemos naquela rubrica, que ressal ta os possíveis efeitos positivos da nova configuração sobre os processos e as situações de trabalho (cf. Castells, 1996). É difícil exagerar a importância dos resultados da guerra cultural que então se abre, já que deles dependea agenda político-institucional da sociedade (cf. Grün, 2003c). Se estivermos diante da maravilhosa "sociedade em rede", louvamos a "flexibilidade" que ela nos permite e tentamos levantar qualquer impedimento, principalmente institucional, que exista (cf. Boltanski e Chiapello, 1999; Powell, 2001). Se, alternativamente, estivermos diante do sombrio mundo da "financeirização", devemos impedir a "precarização", sintoma da doença da dissolução das sociedades nacionais e seus arranjos produtivos e sociais custosamente criados por cada história particular (cf. O rléan, 1999; Froud, H aslam et al., 2000).

Abre-se assim um jogo de nomeação cuja importância intrínseca e cujas nuanças talvez ainda não tenham sido integralmente percebidas. A "flexibilidade" é uma receita sedutora para muitos, principalmente porque torna positivas as características distintivas de diversos grupos em ascensão das elites e das classes médias, como 0 aprendizado precoce de línguas estrangeiras, estratégias de profissionalização ambíguas e renomeação do nosso velho "traquejo social", uma qualidade doméstica desenvolvida nas socializações de elite, em networking capabilities, um trunfo dizível, moderno e diretamente profissional de seus portadores, que agora pode ser avaliado explicitamente em qualquer situação de seleção.

0 reverso necessário da medal ha é que a positivação daquelas qualidades ajuda a desqualificar outros tipos de investimentos pessoais, como a escolarização longa em ramos profissionais mais tradicionais e todas as carreiras que ligam os indivíduos ao Estado. Vai daí que a "flexibilidade", e 
portanto a caracterização do estado presente como 0 advento da "sociedade em rede", tem adeptos natos entre a parcela da população que teria maiores probabilidades de se tornar fazedora de opinião. U m ponto interessante é quenas idéias de "sociedade em rede" as contrações dos universos organizacionais a que estamos assistindo ganham explicações fortes pelo lado dos constrangimentos tecnológicos e, principalmente, pela retomada da velha idéia weberiana da necessidade de nos libertarmos da "gaiola de ferro" da burocracia, esmaecendo o papel e o poder explicativo da pressão financeira. Já a idéia de "financeirização", que acompanha a presente análise, carrega impressões apocalípticas, não só defensivas, mas de defesa contra um inimigo aparentemente insuperável.

Referências Bibliográficas

Actes de la Recherche en Sciences Sociales. (2004), "Georges Soros, les sciences sociales et la régulation du marché mondial", 151-152: 36-48.

Allen, J. (2002), "D eputado defende maiores mudanças na Lei das SAS". 0 Estado de S. Paulo, 19 out.

BalARIN, R. (2004), “M inoritários: fundo, que votou contra união da Ambev com a Interbrew, cobra mais rapidez nas investigações - Previ critica ação da CVM em processos". Valor Econômico, 20 maio.

Batista, R. (2003), "Rosa assume Previ antevendo 'disputas'". Valor Econômico, 25 fev.

Berle, A. A. et al. (1932), The modern corporation and private property. N ova York, M acmillan (trad. bras. [1984], A moderna sociedade anônima e a propriedade privada. São Paulo, Abril Cultural).

Bernstein, P. L. (1992), Capital ideas: the improbable origins of modern Wall Street. N ova York/Toronto, Free Press/M axwell M acmillan Canada/M axwell M acmillan International.

Beunza, D .\& StARK, D . (2004), "Tools of the trade: the socio-technology of arbitrage in a Wall Street trading room". Industrial and Corporate Change, 13 (2): 369-400.

BlaIR, M . M . (2003), "Reforming corporate governance: what history can teach us". Research Paper no 485663. Georgetown, U niversity Law Center.

Boltanski, L. \& ChIAPELlo, E. (1999), Lenouvel esprit du capitalisme. Paris, Gallimard (N RF essais).

BoltAN SKI, L. \& ThÉVEN OT, L. (1991), D ela justification: leséconomiesdela grandeur. Paris, Gallimard.

Bourdieu, P. (2000), Les structures sociales de l'économie. Paris, Seuil (col. Liber). 
Boyer, R. (2003), "L'anthropologie économique de Pierre Bourdieu". Actes de la Recherche en Sciences Sociales, 150: 65-78.

Braga, I. (2003), "Berzoini quer mudança nas normas que restringem investimentos dos fundos de pensão". 0 Globo, 7 jan.

Candido, A. (1987), Os parceiros do Rio Bonito: estudo sobre o caipira paulista e a transformação dos seus meios de vida. São Paulo, Livraria D uas Cidades.

Castells, M . (1996), The rise of the network society. Cambridge, M A, Blackwell Publishers.

Chander, A. D. (1962), Strategy and structure: chaptersin the history of the industrial enterprise. Cambridge, MIT Press.

Cohen, B. J. (1998), The geography of money. Ithaca, Cornell U niversity Press.

Cole, R. E. (1979), Work, mobility, and participation: a comparativestudy of American and Japanese industry. Berkeley, U niversity of California Press.

D'Am вrosio, C. V. E. (2003), "Fundos multimercados voltados para o público de alta renda se multiplicam em velocidade espantosa: quase um novo produto é lançado por dia: os novos VIPS". Valor Econômico, 16 out.

. (2004), "Independentes com patrimônio de R \$ 1 bi: Clube do bilhão". Valor Econômico, 19 jan.

D ÁvILA, S. (2004), "República do Leblon cresce e aparece”. Folha deS. Paulo, 18 jan.

Dezalay, Y. (1994), "Technological warfare: the battle to control the mergers and acquisitions market in Europe". In: D ezalay, Y. (ed.). Professional competition and professional power. Londres, Routledge, pp. 77-103.

. (2004), “Les courtiers de l'international: héritiers cosmopolites, mercenaires de l'impérialisme et missionnaires de l'universel". Actes de la Recherche en Sciences Sociales, 151-152: 5-35.

Dezalay, Y. \& GaRTh, B. G. (2002a), Global prescriptions the production, exportation, and importation of a new legal orthodoxy. Ann Arbor, University of M ichigan Press. . (2002b), The internationalization of palace wars: lawyers, economists, and the contest to transform Latin American states. Chicago, University of Chicago Press (The Chicago Series in Law and Society).

Dezalay, Y. \& Institut des H autes Études Sur La Justice. (1993), Batailles territoriales et querelles de cousinage: juristes et comptables européens sur le marché du droit des affaires. Paris, Librairie Générale de D roit et de Jurisprudence (col. D roit et Société, 7).

Dezalay, Y. \& Sugarman, D. (1994), Professional competition and professional power. Londres/N ova York, Routledge.

D IM AGGIO, P. (2001), The twenty-first-century firm: changing economic organization in international perspective. Princeton, N ova Jersey, Princeton U niversity Press. 
D uarte, S. (2004), "Securitização: fundos de recebíveis se revelam como alternativa barata de captação para as companhias". Revista Capital Aberto, fev.

Elder, G. H . (1999), Children of the great depression: social change in life experience. Boulder, C olorado, Westview Press.

Fama, E. F. (1980), "Agency problems and the theory of firm". Journal of Political Economy, 88 (2): 288-307.

FAORO, R. (1975), Os donos do poder: formação do patronato político brasileiro. Porto Alegre, Editora Globo, 2 vols.

Fligstein, N . (1990), The transformation of corporate control. Cambridge, Mass., $\mathrm{H}$ arvard U niversity Press. . (2001), "T he architecture of markets: an economic sociology of twenty-firstcentury capitalist societies". Princeton, N ova Jersey.

Fligstein, N . \& Friedland, R. (1995), "Theoretical and comparative perspectives on corporate governance". Annual Review of Sociology, pp. 21-43.

Fortunato, D. (2003), "Fundos de pensão divergem sobre investimento em private equity: Pimentel, presidente da Abrapp, defende investimentos de menor risco para os fundos de pensão". Valor E conômico, 8 ago.

Froud, J. et al. (2000), "Shareholder valueand the political economy of late capitalism". Economy and Society, 29 (1): 1-12.

Galbraith , J. K. (1978), The new industrial state. Boston, H oughton M ifflin (trad. bras. [1982], 0 novo estado industrial. São Paulo, Abril Cultural).

Galvão, F. (2004), "Saiba como funcionam os chamados fundos de recebíveis, o novo fenômeno do mercado financeiro no Brasil". Istoé D inheiro, 17 mar.

Gazeta M ercantil. (2001), "C rédito cresce para classes populares", 29 nov.

Gran ovetter, M. S. (1995), Getting a job: a study of contacts and careers. Chicago, University of Chicago Press.

Gran ovetter, M. S. \& Swedberg, R. (1992), The sociology of economic life. Boulder, Westview Press.

G RÜN, R. (1999). "M odel os de empresa, modelos de mundo: sobre al gumas características culturais da nova ordem econômica e da resistência a ela". Revista Brasilei ra de Ciências Sociais, 14: 121-140. . (2003a), "Atores e ações na construção da governança corporativa brasileira". Revista Brasileira de Ciências Sociais, 18 (52): 121-143. . (2003b), "Fundos de pensão no Brasil do final do século XX: guerra cultural, modelos de capital ismo e os destinos das classes médias". M ana, 9 (2): 7-38. . (2003c), "A promessa da 'inserção profissional instigante' da sociedade em rede: a imposição de sentido e a sua sociologia". Dados - Revista de Ciências Sociais, 46 (1): 5-37. 
. (no prelo). "A evolução recente do espaço financeiro no Brasil e al guns reflexos na cena política". Dados - Revista de Ciências Sociais, 47 (1): 5-47.

Guex, S. (2003), "La politique des caisses vides État, finances publiques et mondialisation". Actes de la Recherche en Sciences Sociales, 146-147: 51-61.

Guilh от, N . (2004), “Unevocation philanthropique: G eorgeSoros, les sciences sociales et la régulation du marché mondial". Actes de la Recherche en Sciences Sociales, 151-152, pp. 36-48.

GuILLÉN , M . (2000), “C orporategovernanceand globalization: is there convergence across countries?". Advances in Comparative International M anagement, 13: 175-204.

GuILLÉN, M . F. (1994), M odels of management: work, authority, and organization in a comparative perspective. $C$ hicago, U niversity of Chicago Press.

H ILFERDING, R. (1981), Financecapital: a study of thelatest phase of capitalist devel opment. Londres/Boston, Routledge \& Kegan Paul (trad. bras. [1985], 0 capital financeiro. São Paulo, Abril Cultural).

H ollingsworth , J. R. \& Boyer, R. (1997), Contemporary capitalism: the embeddedness of institutions. Cambridge/N ova York, C ambridge University Press (C ambridge studies in comparative politics).

JACKSON , H . (2001), "An emerging market for corporate control? T he M annesmann takeover and German corporate governance". Trabal ho para discussão. Köln, M ax Planck Institute for the D evelopment of Societies.

Knorr-Cetina, K. \& Bruegger, U . (2002), "Inhabiting technology: the global lifeform of financial markets". Current Sociology, 50 (3): 389-405.

KocH , C. (2001), "Enterprise resource planning: information technology as a steamroller for management politics?". Journal of O rganizational Change M anagement, 14 (1): 64-78.

Laier, P. A. (2004), "Fiesp e BB fecham acordo para desconto de recebíveis". Valor Econômico, 23 abr.

LANE, C. (2003), "C hanges in corporate governance of German corporations: convergence to the Anglo-American model?". Competition and Change, 7 (2-3): 79 100.

Lebaron, F. (2000), La croyance économique: les économistes entre science et politique. Paris, Seuil (Collection Liber).

Leonardo Attuch, R. (2004), "A guerra das ações da Ambev: CPI no Congresso, investigação na CVM , reação dos minoritários: o segundo round da fusão das cervejas". Istoé D inheiro, 24 mar.

LORDON, F. La politique du capital. Paris, O dile Jacob.

M ACKEnZIE, D . (2003a), "An equation and its worlds: bricolage, exemplars, disunity and performativity in financial economics". Social Studies of Science, 33 (6): 831-868. 
. (2003b), "Long-term capital management and the sociology of arbitrage". Economy and Society, 32 (3): 349-380.

. (2003c), "O pening the black box of global finance". Texto apresentado no workshop “A pproaches to G lobal Finance”, U niversity of Warwick, 6-7 dez. 2002. M ACKENZIE, D . \& M ILLO, Y. (2003), "Constructing a market, performing theory: the historical sociology of a financial derivatives exchange". American Journal of Sociology, 109 (1): 107-145.

M ello, E. C. (1995), A fronda dos mazombos: nobres contra mascates, Pernambuco, 1666-1715. São Paulo, Companhia das Letras.

M uRphy, P. (2002), "Esquerda e Bovespa fazem aliança estratégica: para presidente da Bolsa, 'muro de Berlim caiu' com a inédita visita de Lula ao pregão". 0 Estado de S. Paulo, 1 jul.

0 ECD Forum for the Future. (2001), Governancein the $21^{\star}$ century. Paris, 0 rganisation for Economic Co-operation and D evelopment (Future studies).

OrLéan, A. (1999), Le pouvoir de la finance. Paris, O. Jacob.

Paul H IRsch, S. M . \& Friedman, Ray. (1990), "Clean models vs. dirty hands: why economics is different from sociology". In: D IM AGGIO, P. (ed.). Structures of capital: the social organization of theeconomy. N ova York, C ambridge U niversity Press, pp. 39-56.

PowelL, W. W. (2001), "The capitalist firm in the twenty-first-century: emerging patterns in Western enterprise". In: DImAGGIO, P. (ed.). The twenty-first-century firm: changing economic organization in international perspective. Princeton, Princeton University Press, pp. 33-67.

PowelL, W. W. \& DimaggIO, P. (1991), The new institutionalism in organizational analysis. Chicago, University of Chicago Press.

RINGER, F. K. (1969), The German inflation of 1923. N ova York, O xford University Press.

Rıo, C. V. (2004a), "AmBev rebate acusações". Valor Econômico, 6 maio. . (2004b), "Gestoras encerram atividades com fundos". Valor Econômico, 19 maio.

Ro E, M . J. (1994), Strong managers, weak owners, the political roots of American corporate finance. Princeton, Princeton University Press.

. (2003), Political determinants of corporate governance: political context, corporate impact. N ova York, 0 xford University Press.

SAES, F. A. M . (1986), Crédito ebancos no desenvolvimento da economia paulista, 18501930. São Paulo, Instituto de Pesquisas Econômicas.

Schum PETER, J. A. (1991), Theeconomics and sociology of capitalism. N ova Jersey, Princeton University Press. 
Streeck, W. (2001), “La transformation de l'organisation de l'entreprise en Europe: une vue d'ensemble". In: So Low, R. M. (ed.). Institutions et croissance: les chances d'un modèle économique européen. Paris, Albin Michel, pp. 175-230.

Streeck, W. \& Crouch, C. (1997), Political economy of modern capitalism: mapping convergence and diversity. Londres/C alifórnia, Thousand 0 aks/Sage.

The ECon omist. (1994). "Ready to take on the world", 15 jan., pp. 65-66. . (2004), "M inority shareholders in Brazil: a big brewing merger prompts a rethinking of shareholders' rights", 4 mar.

Valor Econômico. (2003a), "Representantes do fundo rebatem as acusações", 1 out. . (2003b), "Brasil estudará menor compulsório, cadastro positivo e autonomia do BC", 16 dez.

VieiRA, H . M . E. C. (2003), "Briga na telefonia: Sérgio Rosa aponta os desacertos entre os sócios e o fundo de investimentos na Brasil Telecom: Previ e BNDES buscam adesões contra O pportunity". Valor Econômico, 1 out.

W eber, M . (1987), La Bolsa: introducción al sistema bursátil. Barcelona, Ariel (1 ed. 1898).

\section{Resumo}

A sociologia das finanças e a nova geografia do poder no Brasil

O súltimos anos assistiram ao desenvolvimento da sociologia das finanças, uma nova especial idade dentro da também nova (ou renovada) sociologia econômica. 0 objetivo do texto é apresentar alguns aspectos da nova área, algumas comparações sobre seu de senvolvimento no espaço de interlocução anglo-saxão com as peculiaridades do seu caminho francês, para depois tentar aplicar alguns desses insights na análise da cena social brasileira contemporânea. Especial atenção é dada à análise da criação simultânea de novos produtos financeiros e novos atores sociais dotados de agendas próprias, não só na esfera econômica, mas também na esfera mais geral de regulação da sociedade. Palavras-chave: Governança corporativa; Sociologia das finanças; Fundos de pensão; Sociologia econômica; Cultura econômica.

\section{Abstract}

Sociology of finance and new geography of power in Brazil

The last years have witnessed the development of Finance Sociology, a new specialty within the also new (or renewed) Economic Sociology. The purpose of the text is to present some aspects of the new area, some comparisons on its development within the Anglo-Saxon dialog field together with the French path's peculiarities, in order to apply some of these insights to the analysis of the Brazilian contemporary social scene. 
Special attention is given to the analysis of the simultaneous creation of new financial products and new social actors endowed with their own agendas, not only in the economic sphere, but also in the more general sphere of society regulation.

Keywords: Corporative government; Finance Sociology; Pension funds; Economic sociology; Economic culture.

Texto recebido em 07/ 2004 e aprovado em $08 / 2004$.

Roberto Grün é professor do D epartamento de Engenharia de Produção da U niversidade Federal de São Carlos desde 1985. Email: rgrun@uol.com.br 